\title{
Brown tumour in the cervical spine : Case report and review of literature
}

\author{
S Carta ${ }^{1}$, A Chungh $^{1}$, SR Gowda*1, E Synodinou ${ }^{2}$, PS Sauve $^{1}$, JR Harvey ${ }^{1}$ \\ ${ }^{1}$ Department of Trauma and Orthopaedics, Queen Alexandra Hospital, Portsmouth Hospitals NHS Trust, UK \\ ${ }^{2}$ Wessex Kidney Centre, Queen Alexandra Hospital, Portsmouth Hospitals NHS Trust, UK
}

Received: September 16, 2019

Accepted: October 18, 2019

Online Published: October 30, 2019

DOI: $10.5430 /$ crcp.v6n1p27

URL: https://doi.org/10.5430/crcp.v6n1p27

\begin{abstract}
Background: Brown tumour of the cervical spine is very rare and is formed due to focal altered bone remodelling secondary to persistent and uncontrolled primary or secondary hyperparathyroidism. It is considered an extreme form of osteitis fibrosa cystica that occurs in the settings of persistently elevated parathyroid hormone. Case Report: This a unique lesion presented in a 48 year old male with recurrent bone pain and known End Stage Renal Disease (ESRD) on maintenance haemodialysis. The main clinical complaints were weak and painful legs and the initial presentation was after the patient collapsed at home and fractured spinal level C2. The initial assessment included blood tests and radiological imaging. CT scanning of the spine revealed a destructive lytic lesion with loss of height and architectural changes of the $\mathrm{C} 2$ vertebral body and cord compression. The differentials included an acute fracture, a metastatic lesion and Brown's tumour. Further imaging with an MRI of the spine and PET-CT were performed which confirmed the above lesion and excluded metastatic disease and bone marrow infiltration. A CT guided bone biopsy followed. The patient continued to receive medical treatment for secondary hyperparathyroidism and the C2 fracture was managed with orthosis through a protective hard collar. Discussion: An up to date literature review revealed very few cases of Brown tumour of the cervical spine and there was only one previous case with $\mathrm{C} 2$ involvement due to primary hyperparathyroidism and one due to secondary hyperparathyroidism. Clinicians must be aware of the varied presentations of Brown's tumour to identify and provide the appropriate management.
\end{abstract}

Key Words: Brown tumour, C2 lesion, Osteitis fibrosa cystica, Secondary hyperthyroidism

\section{INTRODUCTION}

This is a case report of a patient with a brown tumour involving $\mathrm{C} 2$ caused by persistent secondary hyperparathyroidism (HPT). Brown tumour in $\mathrm{C} 2$ is a rare finding and only few cases have been reported in the literature. ${ }^{[1,2]}$ It has been associated with persistently raised levels of parathyroid hormone (PTH). Increased production of PTH from the parathyroid glands leads to a disruption in calcium-phosphate metabolism, causing retention of phosphate alongside a reduction in calcitriol levels. This in turn affects bone remod- elling, with increased osteoclastic activity and fibroblastic proliferation and can affect any part of the skeleton. The incidence rates of brown tumour have been reported from $1.5 \%$ to $13 \%$ in patients with end stage renal disease (ESRD). ${ }^{[1-4]}$

\section{Case history}

\subsection{Presentation}

A 48-year-old gentleman presented with neck pain and progressive weakness in all four limbs after an explained fall at home. He was referred to the oncall Orthopaedic team due

\footnotetext{
*Correspondence: SR Gowda; Email: orthosush@gmail.com; Address: Royal Centre for Defence Medicine, Mindelsohn Way, Birmingham B15 2GW, United Kingdom.
}

Published by Sciedu Press 
to the low energy trauma and paralysis of both upper and lower limbs. The provisional diagnosis was that of cervical spine trauma. His past medical history included ischaemic heart disease, hypertension, end stage renal failure and bipolar disorder. His smoking history was greater than 40 pack years.

\subsection{Examination}

On physical examination there was reduced tone in the upper limbs, with weakness in both upper limb (C5-T1) and lower limb (L2-S1) myotomes. The MRC power grading was 2 in all the myotomes. Sensation was altered to pin prick in the upper and lower limb dermatomes The reflexes were reduced. The patient also had bladder and bowel dysfunction. The patient was alert and orientated in time and place with no features of a cerebro-vascular insult. Blood results confirmed chronic renal failure with raised parathyroid hormone (PTH). This was suggestive of secondary hyperparathyroidism due to chronic kidney disease. He was treated according to the ATLS (Advanced Trauma Life Support) guidelines in the emergency department. Computed tomography (CT) of the spine showed destruction of the left pedicle and body of the $\mathrm{C} 2$ vertebra and a reduction in height of the vertebra. There was disruption of the bony alignment at this level with upper cervical cord compression and there were further lytic lesions seen in the spinous process of $\mathrm{C} 1$, right $\mathrm{T} 1$ and $\mathrm{T} 3$ pedicles and the left 1 st rib. The differential at this point of bony metastases, in view of a pathological C2 fracture and other lytic lesions, was given alongside Brown tumour in the context of chronic kidney disease. CT of his chest, abdomen and pelvis was performed to rule out malignancy (see Figures 1-3).

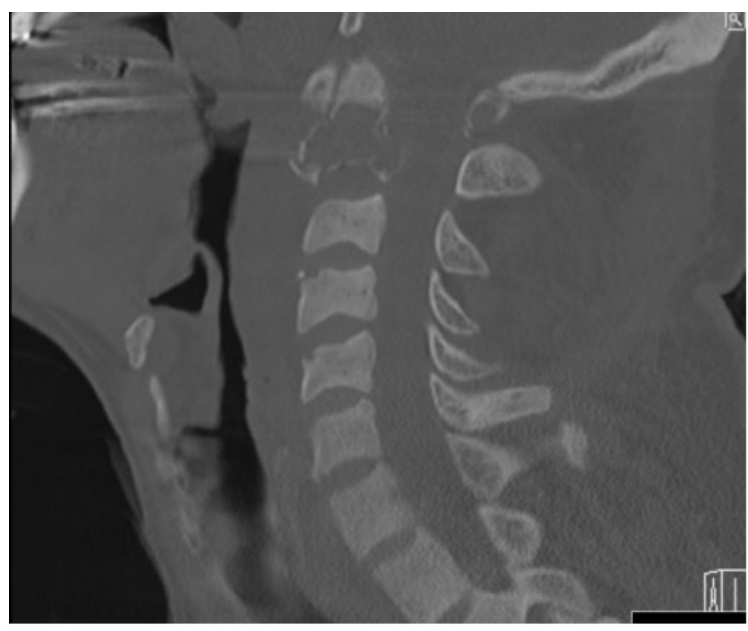

Figure 1. Lesion seen on sagittal CT cervical spine

Multi-nodular goitre was an incidental finding and an ultrasound (USS) of his thyroid was performed, which showed normal appearances of the thyroid with no evidence of parathyroid adenoma. Further nuclear medicine Parathyroid SPECT scan showed no evidence of malignancy. Other investigations included tumour markers, protein electrophoresis, were performed in order to confirm the absence of metastatic disease and bone marrow infiltration. Whilst there is a well understood relationship between renal impairment and primary and secondary hyperparathyroidism, it is necessary to rule out adenoma, hyperplasia and carcinoma in patients who develop primary hyperparathyroidism.

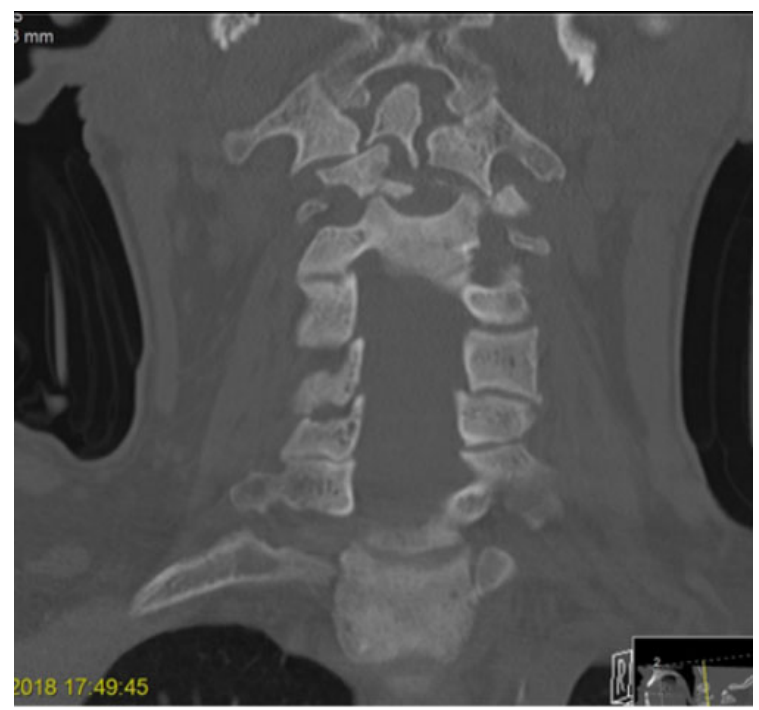

Figure 2. Lesion seen on coronal CT cervical spine

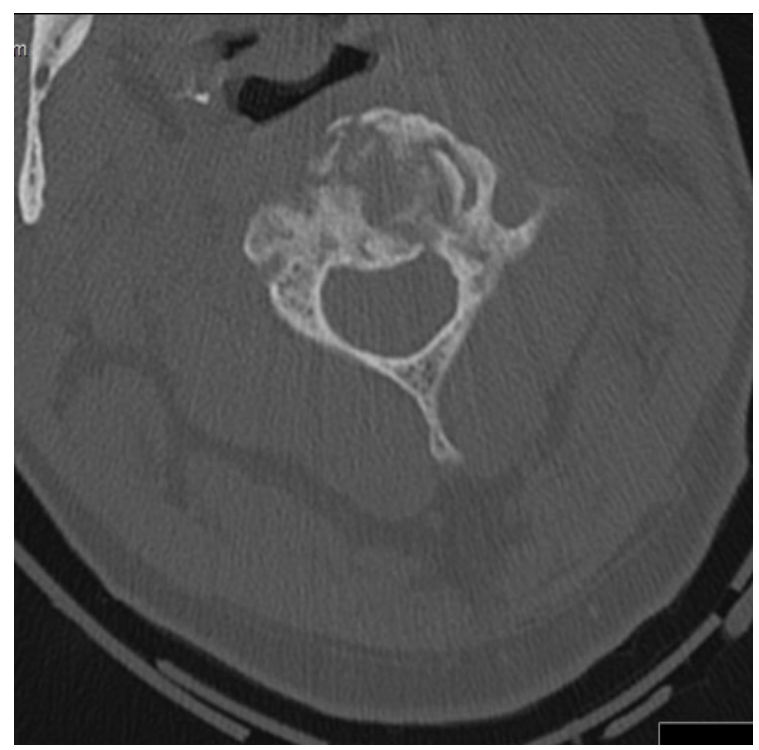

Figure 3. Lesion seen on axial CT cervical spine

After discussion with the regional neurosurgical and spinal unit, a magnetic-resonance imaging (MRI) scan of the cervical spine was performed. This showed a stable pathological 
appearance of $\mathrm{C} 2$ and narrowing of the cervical spine at this level. There was a focal area of central intramedullary hyper signal intensity. Multilevel flavum, ligament and facet hypertrophy from $\mathrm{C} 3$ to $\mathrm{C} 7$ with significant canal stenosis and chronic degenerative changes were also noted. There was no significant foraminal narrowing causing nerve root compression. A CT guided bone biopsy confirmed a significant amount of fibrous tissue, but no giant cells. Endocrinology opinion was sought to address the deranged thyroid and kidney function (see Figures 4-5).

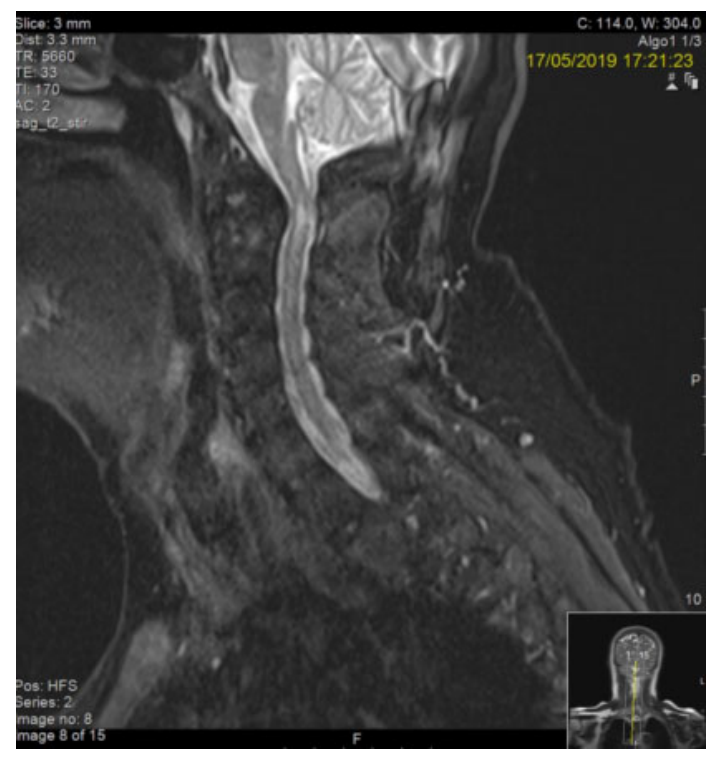

Figure 4. MRI sagittal with ischaemic changes in the cervical spinal cord

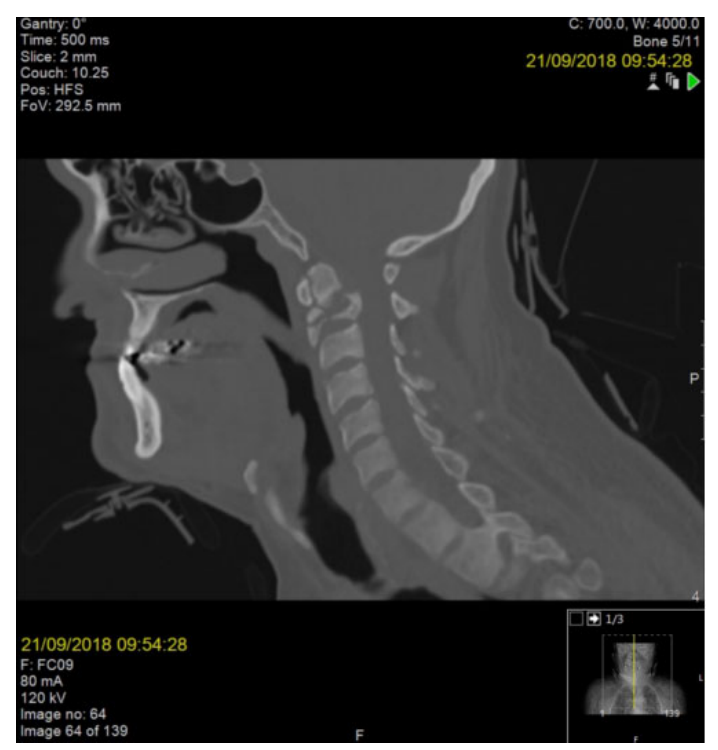

Figure 5. Sagittal CT taken 6 months later
The most probable diagnosis was Brown tumour of the C2 and this was related to persistent secondary hyperparathyroidism and associated ESRD.

\subsection{Management}

The regional neurosurgical centre advised initial management with dexamethasone and a rigid collar for the cervical spine. Orthopaedic review by a local spinal specialist deemed the risk of cervical spine decompression and fusion surgery to be extremely high, and advised for the patient to be managed non-operatively. His fracture was thus managed in an orthosis. The case was reviewed regularly at the MDT meetings in the tertiary neurosurgical and spinal unit.

According to the guidelines and input from Endocrinology team, the patient received medical treatment with both Alfacalcidol and Cinacalcet. Subsequent monitoring confirmed an improvement of his persistently previously elevated PTH level. He also received phosphate binders with relatively good phosphate control.

Four months following the injury, CT scan of the cervical spine was repeated which showed a more expansive lytic lesion with thin walls extending anteriorly and posteriorly compared to the previous CT. There was no further loss of height of the $\mathrm{C} 2$ vertebral body with a better ossified rim of bone anteriorly and posteriorly. Further CT scans confirmed as established non-union of the $\mathrm{C} 2$ fracture. At the most recent follow up in the MDT clinic (22 months after initial presentation), the patient had remarkable improvement in his neurology. no further neurological deterioration. He was able to mobilise with 2 crutches, climb stairs with support and his hand function had improved. Examination by the spinal surgeon revealed a broad based gait with return of upper and lower limb function. The reflexes were found to be brisk but there was no clonus. Bowel function and control had improved. However, the patient still had a urinary catheter insitu. Lateral radiographs in flexion-extension did not show any movement of the fracture.

\section{Discussion}

On review of the available literature on PubMed, six previous cases of Brown tumour involving the cervical spine were identified. Table 1 shows the three previous cases resulting from secondary hyperparathyroidism and three due to primary hyperparathyroidism. ${ }^{[2]}$ Brown tumours in the spine are a rare finding in this particular cohort of patients. 
Table 1. Cases of Browns tumour with spinal involvement

\begin{tabular}{|c|c|c|c|c|}
\hline Author & $\begin{array}{l}\text { Year of } \\
\text { publication }\end{array}$ & $\begin{array}{l}\text { Spinal } \\
\text { involvement }\end{array}$ & $\begin{array}{l}\text { Type of } \\
\text { Hyperparathyroidism }\end{array}$ & Management \\
\hline This report & 2019 & $\mathrm{C} 2$ & Secondary & Medical management + Orthosis \\
\hline Alfawareh (2) & 2015 & $\mathrm{C} 2$ & Primary & Parathyroidectomy + Orthosis \\
\hline Kerstens et al. (3) & 2014 & C7/L3 & Primary & Parathyroidectomy \\
\hline $\begin{array}{l}\text { Khalatbari \& } \\
\text { Moharamzad (4) }\end{array}$ & 2014 & C6 & Primary & Tumour resection + Parathyroidectomy \\
\hline Szeverenyi et al. (5) & 2011 & C7 & Secondary & Tumour resection + Parathyroidectomy \\
\hline Resic et al. (6) & 2011 & C6/7 & Secondary & $\begin{array}{l}\text { Tumour resection }+ \text { Parathyroidectomy }+ \\
\text { spinal stabilisation }\end{array}$ \\
\hline Gheith et al. (7) & 2010 & $\mathrm{C} 4 / 5$ & Primary & Tumour resection + Parathyroidectomy \\
\hline Mateo et al. (8) & 2010 & $\mathrm{C} 2$ & Secondary & Parathyroidectomy + Orthosis \\
\hline Ashebu et al. (9) & 2002 & C6 & Primary & $\begin{array}{l}\text { Parathyroid adenoma resection and } \\
\text { medical therapy }\end{array}$ \\
\hline Barlow \& Archer (10) & 1993 & C5 & Secondary & Parathyroidectomy + Orthosis \\
\hline Grazini et al. (11) & 1991 & C6 & Primary & Parathyroid adenoma resection \\
\hline Ericsson et al. (12) & 1978 & C7-T1 & Secondary & $\begin{array}{l}\text { Parathyroidectomy + Tumour resection + } \\
\text { spine reconstruction }\end{array}$ \\
\hline
\end{tabular}

Brown tumours (also known as osteitis fibrosa cystica) are associated with increased osteoclast activity that result from primary or secondary hyperparathyroidism. ${ }^{[1-7]}$ There is a loss of the bone's trabeculae occurs as a consequence of increased osteoclast activity as well as a reactive proliferation of fibroblasts. The net result is bone of a predisposition to micro fractures and secondary haemorrhage. There is subsequent infiltration of the tissue by osteoclasts and fibrous tissue that gives Brown tumours their characteristic appearance. The macroscopic appearance of the tumour owes to its vascularity, hemosiderin deposition and associated haemorrhage. ${ }^{[8]}$ Whilst parathyroid adenomas remain the largest cause of primary hyperparathyroidism, ESRD remains the greatest risk factors for secondary hyperparathyroidism. Skeletal involvement such as bone cysts, Brown tumours and osteopenia are seen in the late phase of hyperparathyroidism. ${ }^{[9]}$

Brown tumour within the spine primarily presents with pain and neurological deficit, with deficit relating to the spinal level of neuronal compromise. ${ }^{[10]}$ Radiographically, identification is difficult due to the absence of a pathognomonic appearance, often mimicking those of metastases or adenomas. $\mathrm{X}$-ray imaging often demonstrates solitary or multiple lesions that are lytic and normally expansile. The bone cortex may be thinned and expanded but is not necessarily penetrated by the tumour. On CT scanning, a relatively well demarcated soft tissue mass with local bone erosion and expansion is observed. MRI is the modality of choice in evaluating the location, extent of spinal tumour and neural compression. ${ }^{[11]}$ Histological examination provides definitive diagnosis of Brown's tumour. ${ }^{[12]}$

There are updated guidelines by the National Kidney Foun- dation (2017). There are levels established for PTH, calcium, phosphate, and calcium-phosphate products. These treatment guidelines include judicious use of calcium supplements, phosphate binders, and vitamin-D sterols. The regimen must be tailored according to the individual patient and with supervised input of the Endocrinologist / Renal physicians. Lowering PTH levels is paramount and this can also be done by parathyroidectomy when medical regimen has been unsuccessful. However, this can lead to rapid increase in bone mineral density causing further sclerotic lesions elsewhere in the skeleton. ${ }^{[9,13]}$ The main postoperative complication is the 'hungry bone syndrome' which leads to significant hypocalcemia. ${ }^{[11]}$ Parathyroid surgery brings about immediate reduction in PTH levels, thereby achieving complete regression of the bony lesions secondary to remineralisation. ${ }^{[14]}$

A review of literature has revealed only two cases of brown tumour with $\mathrm{C} 2$ involvement caused due to hyperparathyroidism. (Mateo et al, Alfwareh, et al) This has provided a considerable challenge to the spinal and neurosurgeons due to the generalised osteoporosis. ${ }^{[15]}$ Although surgery is indicated when there are severe symptoms and neurological deficit, instability and failure of conservative management. So far, no surgical strategies or techniques have been described to treat brown tumour involving $\mathrm{C} 2$ spine. In the two cases reported by Mateo et al and Alfawareh et al, the patients were also treated with cervical spine orthosis. ${ }^{[2,10]}$

\section{Neurosurgical options}

There is very limited or low level evidence to suggest operative stabilisation to be superior when compared to nonoperative management of degenerate, osteoporotic fracture 
of the $\mathrm{C} 2$ and the sequelae of non-union. Smith et $\mathrm{a}^{[16]}$ found that there were no differences in Neck Disability Index (NDI) scores between elderly patients with regard to union or non-union both at both baseline and 1-year follow up. Similarly, functional outcome scores in patients who underwent posterior fusion showed no significant differences with regard to radiographical fusion or non-union of $\mathrm{C} 2$ fractures in the elderly. ${ }^{[17]}$ A multi-disciplinary meeting involving the patient, neurosurgical, spinal surgeons, anaesthetic team, physician and physiotherapists was held and the options of were discussed. The patient did not wish to pursue the surgical options of decompression and was keen to continue cervical orthosis. He also refused the halo-vest due to its cumbersome nature, associated risks of pneumonia, infection and thromboembolic events. ${ }^{[18]}$

\section{Conclusion}

To our knowledge, this is the third case of brown tumour with $\mathrm{C} 2$ involvement, caused by secondary hyperparathyroidism. Although incidence of Brown's tumour is low, as demonstrated by the review of case reports on PubMed, consideration of these rare sequelae of hyperparathyroidism is prudent in those with ESRD due to the gravity of the potential complications. In those with refractory hyperparathyroidism that is resistant to medical management, a patient-centred multi-disciplinary approach with endocrinologists, endocrine surgeons and spinal surgeons is paramount. This is a unique case of a patient who presented with paralysis from Brown's tumour who has regained adequate function without surgical decompression and stabilisation.

\section{CONFlicts OF InTEREST Disclosure}

The authors declare that they have no competing interest.

\section{REFERENCES}

[1] Vandenbussche E, Schmider L, Mutschler C, et al. Brown tumor of the spine and progressive paraplegia in a hemodialysis patient. Spine. 2004; 29: E251-5. PMid:15187649. https://doi.org/10.1097/ 01.BRS. 0000127187.58944 .FA

[2] Alfawareh MD, Halawani MM, Attia WI, et al. Brown Tumor of the Cervical Spines: A Case Report with Literature Review. Asian Spine J. 2015 Feb; 9(1): 110-120. PMid:25705344. https: //doi.org/10.4184/asj.2015.9.1.110

[3] Kerstens MN, de Vries R, Plukker JT, et al. Multiple skeletal lesions on FDG PET in severe primary hyperparathyroidism. Eur $\mathbf{J}$ Nucl Med Mol Imaging. 2014; 41: 182-3. PMid:23877635. https : //doi.org/10.1007/s00259-013-2509-5

[4] Khalatbari MR, Moharamzad Y. Brown tumor of the spine in patients with primary hyperparathyroidism. Spine (Phila Pa 1976). 2014; 39 : E1073-9. PMid:24921845. https://doi.org/10.1097/BRS. 00 00000000000455

[5] Szeverenyi C, Dezso B, Demenyi T, et al. Vertebral brown tumor in childhood (case report). Surg Sci. 2011; 2: 344-7. https: //doi.org/10.4236/ss.2011.26074

[6] Resic H, Masnic F, Kukavica N, et al. Unusual clinical presentation of brown tumor in hemodialysis patients: two case reports. Int Urol Nephrol. 2011; 43: 575-80. PMid:20424916. https: //doi.org/10.1007/s11255-010-9738-3

[7] Gheith O, Ammar H, Akl A, et al. Spinal compression by brown tumour in two patients with chronic kidney allograft failure on maintenance hemodialysis. Iran J Kidney Dis. 2010; (4): 256-9.

[8] Ashebu SD, Dahniya MH, Muhtaseb SA, et al. Unusual florid skeletal manifestations of primary hyperparathyroidism. Skeletal Radiol. 2002; 31: 720-723. PMid:12483435. https ://doi.org/10. 100 7/s00256-002-0578-9

[9] Agarwal G, Mishra SK, Kar DK, et al. Recovery pattern of patients with osteitis fibrosa cystica in primary hyperparathyroidism after successful parathyroidectomy. Surgery. 2002; 132: 1075-85.
PMid:12490858. https://doi.org/10.1067/msy.2002.12848 4

[10] Mateo L, Massuet A, Sola M, et al. Brown tumor of the cervical spine: a case report and review of the literature. Clin Rheumatol 2011; 30: 419-424. PMid:20981561. https://doi .org/10.100 7/s10067-010-1608-y

[11] Slatopolsky E, Gonzalez E, Martin K. Pathogenesis and treatment of renal osteodystrophy. Blood Purif. 2003; 21: 318-26. PMid:12944733. https://doi.org/10.1159/000072552

[12] Maitra A, Abbas AK. The endocrine system. In: Kumar V, Abbas AK, Fausto N, editors. Robbins \& Cotran pathologic basis of disease, 7th ed. Philadelphia: Elsevier Saunders; 2005: 1155-226.

[13] National Kidney Foundation. K/DOQI clinical practice guidelines for bone metabolism and disease in chronic kidney disease. Am J Kidney Dis. 2003; 42(4 Suppl 3): S1-201.

[14] Tarrass F, Ayad A, Benjelloun M, et al. Cauda equina compression revealing brown tumor of the spine in a long-term hemodialysis patient. Joint Bone Spine. 2006; 73: 748-50. PMid:16650789. https://doi.org/10.1016/j.jbspin.2006.01.011

[15] Kaya RA, Cavusoglu H, Tanik C, et al. Spinal cord compression caused by a brown tumor at the cervicothoracic junction. Spine J. 2007; 7: 728-32. PMid:17998132. https://doi.org/10.1016/ j.spinee.2006.07.013

[16] Smith JS, Kepler CK, Kopjar B, et al. The effect of type II odontoid fracture nonunion on outcome among elderly patientstreated without surgery. Spine. 2013; 38(26): 2240-2246.

[17] Molinari RW, Dahl J, Gruhn WL, et al. Functional outcomes, morbidity, mortality, and fracture healing in 26 consecutive geriatric odontoid fracture patients treated with posterior fusion. Journal of Spinal Disorders and Techniques. 2013; 26(3): 119-126. PMid:22143048. https://doi.org/10.1097/BSD.0b013e31823e99e4

[18] Majercik S, Tashjian RZ, Biffl WL, et al. Halo vest immobilization in the elderly: a death sentence? Journal of Trauma. 2005; 59(2): 350-357. PMid:16294074. https://doi.org/10.1097/ 01. ta. $0000174671.07664 .7 \mathrm{c}$ 